\title{
Atribuições dos Profisssionais de Psicologia na Política de Adoção
}

\author{
Leonam Amitaf Ferreira Pinto de Albuquerque* \\ Universidade Federal da Paraíba - UFPB, João Pessoa, PB, Brasil \\ ORCID: http://orcid.org/0000-0003-1075-8344 \\ Noêmia Soares Barbosa Leal** \\ Universidade Federal da Paraíba - UFPB, João Pessoa, PB, Brasil \\ ORCID: https://orcid.org/0000-0001-8389-7834 \\ Maria de Fátima Pereira Alberto*** \\ Universidade Federal da Paraíba - UFPB, João Pessoa, PB, Brasil \\ ORCID: https://orcid.org/0000-0003-2515-9571
}

\begin{abstract}
RESUMO
O objetivo deste estudo foi analisar as ações atribuídas pelas normativas da política de adoção aos profissionais de Psicologia da Vara da Infância e Juventude. Foram submetidos à análise documental o Estatuto da Criança e do Adolescente, a Lei Nacional da Adoção, o provimento do Conselho Nacional de Justiça sobre as Varas da Infância e Juventude e a resolução do Conselho Federal de Psicologia sobre a atuação do psicólogo como perito e assistente técnico no Poder Judiciário. Os dados foram analisados por meio da técnica de Análise de Conteúdo Temática. As ações atribuídas pelas normativas da política de adoção aos profissionais de Psicologia contribuem para fundamentar as decisões judiciais, avaliar os pretendentes, auxiliar durante o processo, acolher e escutar suas angústias. Também colaboram para prestar assistência qualificada e integral, oferecer suporte psicológico, legal e social e proporcionar espaços permanentes de reflexão a todos os envolvidos. A vasta quantidade de atribuições e sua natureza técnica podem gerar sobrecarga de trabalho para esses profissionais, cuja formação acadêmica ofertada no Brasil continua atrelada a campos tradicionais.
\end{abstract}

Palavras-chave: adoção, psicólogos, psicologia jurídica.

\section{Attributions of Psychology Professionals in the Policy of Adoption}

\begin{abstract}
The objective of this study is to analyze the actions attributed by the norms of the policy of adoption to Psychology Professionals of the Court of Childhood and Youth. The Statute of the Child and Adolescent, the National Adoption Law, the provision of the National Council of Justice on the Courts of Childhood and Youth and the resolution of the Federal Council of Psychology on the performance of the psychologist as an expert and technical assistant in the Judiciary were submitted to the document analysis. Data were analyzed using the Thematic Content Analysis technique. The actions attributed by the norms of the policy of adoption to Psychology Professionals contribute to substantiate judicial decisions, evaluate applicants, assist during the process, comfort and listen to their anxieties. They also collaborate to
\end{abstract}


provide qualified and comprehensive assistance, provide psychological, legal and social support and provide permanent spaces for reflection to all involved. The vast amount of assignments and their technical nature can generate work overload for these professionals, whose academic training offered in Brazil remains linked to traditional fields.

Keywords: adoption, psychologists, juridical psychology.

\section{Atribuciones de los Profesionales de Psicología en la Política de Adopción}

\section{RESUMEN}

El objetivo de este estudio es analizar las acciones atribuidas por las normativas de la política de adopción a los profesionales de Psicología de la Vara de la Infancia y la Juventud. Fueron sometidos al análisis de documentos el Estatuto del Niño y del Adolescente, la Ley Nacional de la Adopción, la provisión del Consejo Nacional de Justicia sobre las Varas de la Infancia y Juventud y la resolución del Consejo Federal de Psicología sobre la actuación del psicólogo como experto y asistente técnico en el Poder Judicial. Los datos se analizaron utilizando la técnica de Análisis de Contenido Temática. Las acciones atribuidas por las normativas de la política de adopción a los profesionales de Psicología contribuyen a fundamentar decisiones judiciales, evaluar a los solicitantes, ayudar durante el proceso, acoger y escuchar sus ansiedades. También colaboran para brindar asistencia calificada e integral, brindar apoyo psicológico, legal y social y proporcionar espacios permanentes de reflexión a todos los involucrados. La gran cantidad de tareas y su naturaleza técnica pueden generar una sobrecarga de trabajo para estos profesionales, cuya capacitación académica ofrecida en Brasil sigue vinculada a los campos tradicionales.

Palabras clave: adopción, psicólogos, psicología jurídica.

Este estudo teve por objetivo analisar as ações atribuídas pelas normativas da política de adoção aos profissionais de Psicologia da Vara da Infância e Juventude. A garantia da convivência familiar e comunitária, em que se assenta a política de adoção, é resultante do movimento das lutas democráticas pelo reconhecimento da manutenção dos vínculos familiares como direito de todas as crianças e adolescentes e dever do Estado brasileiro. Esse direito foi assegurado pela Constituição Federal de 1988 e regulamentado pelo Estatuto da Criança e do Adolescente (ECA), de 1990, pela Lei Nacional de Adoção (LNA), de 2009, e pela atualização da Lei Nacional de Adoção, de 2017.

A política de garantia do direito das crianças e adolescentes à convivência familiar e comunitária, prevista no texto do ECA, dispõe de três medidas sociojurídicas: a) manutenção e reintegração familiar; b) acolhimento institucional; e c) colocação em família substituta (Lei 
n. 12.010, 2009). Esta última medida abarca os institutos de guarda, tutela e adoção, os quais devem ser acompanhados por equipes técnicas da Justiça da Infância e Juventude, com o apoio dos responsáveis pela execução da política municipal de convivência familiar e comunitária (Lei n. 13.509, 2017). A adoção aparece, assim, na legislação vigente como uma ação isolada, ao lado de outras medidas legais do Poder Judiciário, e não como uma política pública, articulada e integrada às demais.

A Justiça da Infância e Juventude é composta por diversos órgãos de garantia de direitos, como as Promotorias e Delegacias especializadas, os Conselhos Tutelares e as Varas da Infância e Juventude. Compete a estas últimas proteger os direitos das crianças e adolescentes por meio de ações civis edificadas nos interesses individuais, difusos ou coletivos referentes a esse público (Lei n. 8.069, 1990). No contexto da política de adoção, a Vara da Infância e Juventude tem como papel habilitar os interessados em adotar, por meio da avaliação técnica de aspectos jurídicos e psicossociais, determinando quem pode ou não seguir o caminho da adoção (Silva \& Arpini, 2013; Valério \& Lyra, 2014).

A avaliação dos pretendentes à adoção é realizada pelas equipes técnicas das Varas da Infância e Juventude, constituídas por psicólogos, assistentes sociais, pedagogos, que têm como atribuições assessorar a autoridade judiciária mediante a elaboração de documentos e a realização de aconselhamentos, orientações, encaminhamentos e medidas de prevenção (Lei n. 8.069, 1990). Como explicam Montenegro, Rocha e Francileudo (2017) e Pereira, Torres, Falcão e Pereira (2013), esses profissionais fornecem subsídios por escrito, mediante laudos, pareceres e relatórios, ou verbalmente, nas audiências, com base em conhecimento amplo sobre o desenvolvimento da infância e adolescência e a configuração das relações familiares.

O Provimento do Conselho Nacional de Justiça (CNJ) n. 36 (2014) recomenda às equipes do Judiciário que envidem os esforços necessários para acelerar a avaliação técnica dos processos de adoção, habilitação e destituição do poder familiar e a reavaliação da situação jurídica e psicossocial das crianças e adolescentes acolhidos. Diante dessas exigências, os profissionais da equipe técnica da Vara da Infância e Juventude são levados a refletirem acerca dos desdobramentos de sua atuação sobre a vida de todos os envolvidos, principalmente crianças, adolescentes e seus familiares, cuja garantia do direito ao convívio familiar e comunitário depende do resultado de suas decisões (Morelli, Scorsolini-Comin, \& Santeiro, 2015).

Em relação ao processo de habilitação para a adoção, a Lei Nacional da Adoção (Lei n. $12.010,2009)$ determina que este implique a obrigatoriedade de participação dos pretendentes em programa preparatório oferecido pela equipe da Vara da Infância e 
Juventude, com o auxílio dos técnicos da política municipal de convivência familiar e comunitária. Conforme reforçam Otuka, Scorsolini-Comin e Santos (2013) e Valério e Lyra (2014), a orientação jurídica e psicossocial sobre a adoção não constitui apenas uma etapa da habilitação, como é previsto na legislação vigente, mas um espaço permanente de reflexão e acolhida dos pretendentes, seus familiares e demais envolvidos no processo de adoção.

No que se refere à atuação dos profissionais de Psicologia na equipe da Vara da Infância e Juventude, conforme a Resolução do Conselho Federal de Psicologia (CFP) n. 008 (2010), compete aos psicólogos peritos subsidiar a autoridade judiciária por meio de aportes teóricos, técnicos e metodológicos, fundados na área do conhecimento da Psicologia. Segundo Montenegro et al. (2017) e Morelli, Scorsolini-Comin e Santeiro (2015), embora estes profissionais devam se isentar em relação às partes, o acolhimento e escuta proporcionados por eles possibilita a preparação dos envolvidos no processo de adoção por meio da elaboração de suas motivações e expectativas e a construção de espaços de apoio e troca de experiências e conhecimentos sobre adoção, o que vai além da função de perícia.

Como pode ser visto, o ECA, a LNA, as normas do CNJ e do CFP, entre outras normativas da política de adoção, atribuem um conjunto de ações aos profissionais de Psicologia que compõem a equipe técnica da Vara da Infância e Juventude. Essas atribuições vão desde a realização de avaliações, estudos, aconselhamentos, encaminhamentos e habilitações até a elaboração de documentos, com o fim de auxiliar a autoridade judiciária na tomada de decisões. Tendo em vista esses aspectos, emergiram os seguintes questionamentos: qual a natureza das ações atribuídas aos psicólogos pelas normativas da política de adoção? Quais os desdobramentos dessas atribuições sobre os direitos das crianças e adolescentes? Como elas favorecem a efetivação da política de adoção? Este estudo busca elucidar essas questões, pertinentes ao tema da adoção, a partir de reflexões acerca da atuação dos profissionais de Psicologia no contexto judiciário junto à política de adoção.

\section{Método}

Foi utilizada como técnica de coleta de dados a análise documental, modalidade de pesquisa que tem como finalidade explorar e analisar fontes documentais que podem ser reelaboradas de acordo com os objetivos de investigação (Gil, 2008). Entre suas limitações, estão a dificuldade de acesso a certos documentos, a escassez de informações detalhadas e a possibilidade de os dados estarem falseados (Sá-Silva, Almeida, \& Guindani, 2009). Esta técnica permitiu identificar as ações atribuídas pelas normativas da política de adoção aos 
profissionais de Psicologia, viabilizando a composição das informações coletadas como objeto de consulta e análise.

$\mathrm{Na}$ etapa de preparação do roteiro da análise documental, como recomenda Minayo (2007), foram selecionados os tipos de documentos que seriam submetidos ao tratamento analítico, a natureza das fontes documentais e as modalidades de informação coletada: materiais primários, em formato escrito, disponíveis no meio virtual. As fontes documentais escolhidas foram baixadas e armazenadas dos sítios eletrônicos do Planalto (http://www.planalto.gov.br/), do Conselho Nacional de Justiça (http://www.cnj.jus.br/) e do Conselho Federal de Psicologia (http://site.cfp.org.br/).

Foram submetidos à análise documental a Lei n. 8.069 (1990), que instaura o ECA, a Lei n. 12.010 (2009), denominada Lei Nacional da Adoção, o Provimento do CNJ n. 36 (2014) e a Resolução do CFP n. 008 (2010). Essas normativas dispõem sobre a proteção integral das crianças e adolescentes, o aperfeiçoamento da garantia do direito à convivência familiar, as condições estruturais e os procedimentos das Varas da Infância e Juventude e a atuação do psicólogo como perito e assistente técnico no Poder Judiciário. Elas atribuem um conjunto de ações aos profissionais de Psicologia da Vara da Infância e Juventude de modo que estes auxiliem a autoridade judiciária na tomada de decisões junto à política de adoção.

Os dados resultantes da análise desses documentos foram submetidos à Análise de Conteúdo Temática (Bardin, 2011; Minayo, 2009), técnica de análise qualitativa em pesquisa social que se divide em três fases abrangentes e flexíveis: 1) leitura compreensiva e exaustiva do material selecionado; 2) exploração do material estruturado em classes temáticas, categorias e subcategorias ou análise propriamente dita; e 3) elaboração de síntese interpretativa sobre o material explorado.

A partir da leitura pormenorizada das fontes documentais, foi estruturado um corpus de análise para fundamentar a descrição e interpretação dos recortes de texto do material selecionado. Em seguida, esses segmentos foram distribuídos em esquemas de classificação inicial, agrupados em classes temáticas e categorias, e interpretados a partir da literatura pertinente ao tema de investigação. Por fim, foi elaborada uma síntese das interpretações realizadas nas etapas anteriores, estabelecendo o diálogo entre as temáticas levantadas, a revisão bibliográfica e a lógica interna do conjunto do material explorado.

Convém ressaltar que este estudo cumpriu rigorosamente as normas e princípios éticos de pesquisa, estabelecidos pela Resolução do Conselho Nacional de Saúde (CNS) n. 466 (2012), sendo submetido à apreciação e avaliação do Comitê de Ética em Pesquisa (CEP) da 
Universidade Federal da Paraíba (UFPB), no qual foi aprovado sob o número de protocolo 85301618.0.0000.518.

\section{Resultados e Discussão}

As ações atribuídas pelas normativas da política de adoção aos profissionais de Psicologia da Vara da Infância e Juventude foram distribuídas em classes temáticas e categorias a posteriori, construídas a partir da análise dos dados coletados, como pode ser observado na Tabela 1: 
Leonam Amitaf Ferreira Pinto de Albuquerque, Noêmia Soares Barbosa Leal, Maria de Fátima Pereira Alberto

Tabela 1

Ações Atribuidas pelas Normativas da Politica de Adoção aos Profissionais de Psicologia da Vara da Infância e Juventude

\begin{tabular}{|c|c|}
\hline Classes temáticas & Categorias \\
\hline \multirow[t]{3}{*}{ Elaborar documentos } & Relatório \\
\hline & Laudo \\
\hline & Parecer \\
\hline Desenvolver atividades & Estudo \\
\hline técnicas & Pericia \\
\hline Prestar assistência & Gestantes \\
\hline psicológica & Mães adolescentes \\
\hline \multirow[t]{2}{*}{ Realizar oitivas } & Genitores \\
\hline & Crianças e adolescentes \\
\hline \multirow[t]{3}{*}{ Estabelecer parcerias } & Equipes técnicas municipais \\
\hline & Peritos \\
\hline & Equipes multiprofissionais \\
\hline \multirow[t]{4}{*}{ Acompanhar } & Crianças e adolescentes indígenas \\
\hline & Pretendentes à adoção \\
\hline & Estágio de convivência \\
\hline & Colocação em familia substituta \\
\hline \multirow[t]{4}{*}{ Orientar } & Inscrição de postulantes à adoção \\
\hline & $\begin{array}{l}\text { Contato com crianças e adolescentes em condições de } \\
\text { serem adotados }\end{array}$ \\
\hline & Consentimento dos titulares do poder familiar \\
\hline & Familia substituta \\
\hline \multirow[t]{5}{*}{ Preparar } & Contato com crianças e adolescentes em acolhimento \\
\hline & familiar ou institucional \\
\hline & Programa oferecido pela Justiça da Infância e da \\
\hline & Juventude \\
\hline & Pessoas e casais inscritos nos cadastros de adoção \\
\hline
\end{tabular}

Entre as atribuições dos profissionais de Psicologia na política de adoção estão a elaboração de relatórios, laudos e pareceres; o desenvolvimento de estudos e perícias; a prestação de assistência psicológica a gestantes e mães adolescentes; a realização de oitivas com genitores e crianças e adolescentes; o estabelecimento de parcerias com equipes técnicas municipais, peritos e assistentes técnicos e equipes multiprofissionais; e o acompanhamento das crianças e adolescentes indígenas, dos pretendentes à adoção, do estágio de convivência e da colocação em família substituta. 
Também foram identificadas como atribuições desses profissionais da Vara da Infância e Juventude a orientação da inscrição de postulantes à adoção, do contato com crianças e adolescentes em condições de serem adotados, do consentimento dos titulares do poder familiar e da família substituta; e a preparação das pessoas e casais inscritos nos cadastros de adoção por meio do contato com crianças e adolescentes em acolhimento familiar ou institucional e de programa oferecido pela Justiça da Infância e da Juventude. Nos tópicos que seguem, as classes temáticas e suas respectivas categorias são definidas e discutidas à luz das referências adotadas nesse estudo.

\section{Elaboração de documentos}

A classe temática Elaborar documentos aborda os documentos produzidos pelos profissionais de Psicologia enquanto membros da equipe técnica da Vara da Infância e Juventude, a fim de embasar a decisão judicial sobre os casos de reintegração familiar, colocação em família substituta e acolhimento institucional de crianças e adolescentes. Nessa classe, estão presentes as categorias Relatório, Laudo e Parecer.

O Relatório consiste na descrição dos procedimentos adotados e resultados alcançados ao longo da intervenção profissional do psicólogo em diferentes processos de trabalho, possuindo caráter informativo e não tendo como finalidade produzir diagnóstico psicológico (Resolução CFP n. 06, 2019). Ao situar os desdobramentos das atividades desenvolvidas pelos profissionais de Psicologia com as crianças e adolescentes em condições de serem adotados, conforme estabelece o $\S 1^{\circ}$ do artigo 19 do ECA (Lei n. 8.069, 1990), este documento permite à autoridade judiciária visualizar as circunstâncias das intervenções realizadas e, assim, avaliar a conveniência do deferimento das medidas de reintegração familiar e colocação em família substituta.

O Laudo é resultante da avaliação psicológica e apresenta os procedimentos adotados pelo profissional de Psicologia no decorrer desse processo, as conclusões geradas e as informações técnicas e científicas dos fenômenos psicológicos, tendo por objetivo a elaboração do diagnóstico psicológico (Resolução CFP n. 06, 2019). Este documento inclui os resultados da avaliação dos pretendentes à adoção pelos psicólogos da equipe técnica da Vara da Infância e Juventude que, com base nas informações fornecidas, relacionadas à demanda, e ao final do prazo determinado pela legislação pertinente, "recomendará ou não o deferimento da adoção à autoridade judiciária” (Lei n. 8.069, 1990, art. 46, § 3º-A). 
O Parecer constitui em um pronunciamento perante uma consulta, cujo objetivo é apresentar uma análise técnica do psicólogo com respostas a uma questão-problema do campo psicológico ou a documentos psicológicos questionados, não sendo resultante de intervenção psicológica ou avaliação psicológica (Resolução CFP n. 06, 2019). Este documento, elaborado pelos profissionais de Psicologia, permite à equipe técnica da Vara da Infância e Juventude e à autoridade judiciária dirimirem suas dúvidas acerca da preparação e nível de compreensão das crianças e adolescentes consultados "por meios adequados ao seu estágio de desenvolvimento", como previsto no inc. III, $\S 1^{\circ}$, do art. 51 do Estatuto da Criança e do Adolescente (Lei n. 8.069, 1990), sobre a viabilidade da colocação em família substituta.

Como se depreende da análise dessas categorias, que distinguem os documentos produzidos pelo psicólogo no exercício profissional (Resolução CFP n. 06, 2019), e da contribuição de Montenegro et al. (2017) e Pereira et al. (2013), a documentação resultante das atividades desempenhadas pelos profissionais de Psicologia na política de adoção oferece subsídios para fundamentar as decisões judiciais referentes à garantia do direito das crianças e adolescentes à convivência familiar e comunitária. Conforme explicam esses autores, no Brasil, quando alguém decide adotar uma criança ou adolescente, precisa ser entrevistado por psicólogos e assistentes sociais da Vara da Infância e Juventude que, com base na avaliação dos pretendentes, emitirão documento favorável ou contrário ao andamento da habilitação para a adoção, respaldando a decisão da autoridade judiciária.

\section{Desenvolvimento de atividades técnicas}

A classe temática Desenvolver atividades técnicas aborda as atividades realizadas pela equipe técnica da Vara da Infância e Juventude com o intuito de fundamentar os processos de adoção, contribuindo para avaliar a capacidade da família de origem e dos postulantes brasileiros e estrangeiros para o exercício da paternidade ou maternidade. Essa classe contempla as categorias Estudo e Perícia.

O Estudo versa sobre a atividade técnica, resultante de avaliação psicológica ou social, desenvolvida pela equipe da Vara da Infância e Juventude que, como determina o $\operatorname{artigo~} 2^{\circ}$ da Lei Nacional da Adoção (Lei n. 12.010, 2009), oferece subsídios teórico-científicos para analisar os processos de adoção, habilitação para adoção, destituição do poder familiar e acolhimento institucional de crianças e adolescentes.

A Perícia trata da atividade técnica desenvolvida pela equipe técnica da Vara da Infância e Juventude com a finalidade de subsidiar a decisão judicial sobre os casos de 
"suspensão ou destituição do poder familiar" (Lei n. 12.010, 2009, art. 2º ). De acordo com o artigo $3^{\circ}$ da Resolução do CFP n. 008 (2010), “conforme a especificidade de cada situação, o trabalho pericial poderá contemplar observações, entrevistas, visitas domiciliares e institucionais, aplicação de testes psicológicos, utilização de recursos lúdicos e outros instrumentos, métodos e técnicas reconhecidas pelo Conselho Federal de Psicologia".

Por meio de uma extensa investigação sobre a prática de psicólogos na Vara da Infância e Juventude junto aos processos de adoção, Montenegro et al. (2017) reúnem um conjunto de atividades técnicas desempenhadas nesse ambiente por esses profissionais, cujo trabalho pericial (Resolução CFP n. 008, 2010) abrange a preparação para a adoção, a avaliação psicossocial, a realização de perícias, estudos, entrevistas e visitas, a produção de documentos e a participação em audiências. Ao analisarem algumas dessas atividades, em especial a avaliação psicossocial dos pretendentes, Valério e Lyra (2014) concluíram que a atuação dos psicólogos no contexto jurídico pode ser um importante catalisador de mudanças para os envolvidos no processo de adoção, mas também pode ser precursor de arbitrariedade, uma vez que estes são responsáveis por avaliar positiva ou negativamente, determinando quem pode ou não adotar.

\section{Prestação de assistência psicológica}

A classe temática Prestar assistência psicológica remete ao dever do Poder Público de prestar assistência psicológica e especializada, por meio da equipe técnica da Vara da Infância e Juventude, às gestantes e mães adolescentes, antes e depois do nascimento da criança, de modo a diminuir os riscos do puerpério. Nessa classe, foram identificadas as categorias Gestantes e Mães adolescentes.

As Gestantes compreendem a prestação de assistência psicológica a esse público "no período pré e pós-natal, inclusive como forma de prevenir ou minorar as consequências do estado puerperal" (Lei n. 12.010, 2009, art. $2^{\circ}$ ). As Mães adolescentes abrangem a prestação de assistência psicológica a esse grupo "por equipe especializada multidisciplinar" (Lei n. 8.069, 1990, art. 19, $\S 6^{\circ}$ ). Segundo contribuição do Conselho Federal de Psicologia (1992) ao Ministério do Trabalho para integrar o catálogo brasileiro de ocupações, entre as atribuições do profissional de Psicologia, está o acompanhamento psicológico de gestantes durante a gravidez, parto e puerpério, procurando integrar suas vivências emocionais e corporais, bem como incluir o parceiro como apoio necessário em todo este processo. 
Os desdobramentos da análise dessas categorias coadunam com o que reforçam Silva e Arpini (2013), para os quais, além dos postulantes e das crianças e adolescentes em condições de serem adotados, também precisam ser assistidos por especialistas em infância, adolescência e família os membros das famílias de origem e extensa, como as gestantes e mães adolescentes, no decorrer das fases gestacionais (CFP, 1992), pois estes constituem o cerne do direito à convivência familiar e comunitária. Na mesma direção, Morelli et al. (2015) apontam os benefícios do apoio psicológico para todos os envolvidos no processo de adoção, o que permite que as exigências em relação à criança sejam flexibilizadas, angústias sejam acolhidas, medos compartilhados e diversas dúvidas sejam devidamente esclarecidas, favorecendo a garantia do convívio familiar e comunitário.

\section{Realização de oitivas}

A classe temática Realizar oitivas abrange a oitiva prévia de genitores e crianças e adolescentes pela equipe técnica da Vara da Infância e Juventude, a fim de considerar a opinião destes sobre a medida tomada, respeitado seu estágio de desenvolvimento e grau de compreensão, e acompanhar o processo de desistência por aqueles da entrega da criança após o nascimento. Essa classe contém as categorias Genitores e Crianças e adolescentes.

Os Genitores compreendem a realização de oitivas com esse público sobre a desistência da entrega da criança recém-nascida, a qual deverá permanecer com o mesmo, sob acompanhamento familiar da equipe técnica da Vara da Infância e Juventude. Em seu art. 19A, $\S 8^{\circ}$, o ECA (Lei n. 8.069, 1990) determina que diante da ocorrência de desistência da entrega da criança após o nascimento, o acompanhamento referido "será determinado pela Justiça da Infância e da Juventude pelo prazo de 180 (cento e oitenta) dias”.

As Crianças e adolescentes abrangem a realização de oitivas prévias com esse grupo pela equipe técnica da Vara da Infância e Juventude, "respeitado seu estágio de desenvolvimento e grau de compreensão sobre as implicações da medida" (Lei n. 12.010, 2009, art. $2^{\circ}$ ) e devidamente considerada sua opinião. Este mesmo artigo da Lei Nacional da Adoção reforça que no caso de adolescentes maiores de doze anos de idade, faz-se necessário seu consentimento, colhido em audiência com a autoridade judiciária competente.

A análise dessas categorias converge com os escritos de Valério e Lyra (2014), conforme os quais a preparação para a adoção constitui um período permanente de acolhimento e escuta dos interesses das partes envolvidas, implicando não apenas os pretendentes e as crianças e adolescentes (Lei n. 12.010, 2009, art. $2^{\circ}$ ), mas também a família 
de origem, que pode vir a desistir da entrega para a adoção (Lei n. 8.069, 1990, art. 19-A, § $\left.8^{\circ}\right)$. Sobre o exercício da escuta qualificada pelos membros da equipe técnica, Montenegro et al. (2017) salientam que se o falar não for compreendido em suas vicissitudes, quanto ao desenvolvimento psicológico, social e cognitivo, através de uma postura de acolhimento e disposição para escutar, o conteúdo da comunicação pode ser distorcido e o diálogo entre os envolvidos interditado.

\section{Estabelecimento de parcerias}

A classe temática Estabelecer parcerias refere-se ao estabelecimento de relações de proximidade e parceria da equipe técnica da Vara da Infância e Juventude com as equipes técnicas municipais, os peritos e as equipes multiprofissionais a fim de aprimorar as intervenções protetivas, atendimentos e acompanhamentos junto às crianças, adolescentes e suas famílias, impedindo intervenções no decorrer do processo avaliativo que possam comprometer a garantia da autonomia entre os profissionais envolvidos. Nessa classe, estão presentes as categorias Equipes técnicas municipais, Peritos e Equipes multiprofissionais.

As Equipes técnicas municipais tratam do estabelecimento de parcerias da equipe técnica da Vara da Infância e Juventude com as equipes técnicas que atuam nos municípios, formadas por profissionais de Psicologia, Serviço Social e Direito, com vistas a garantir a efetividade e prioridade da proteção, atendimento e acompanhamento das crianças, adolescentes e suas famílias pelo Poder Público, conforme dispõe o inciso I do artigo $6^{\circ}$ do Provimento do CNJ n. 36 (2014).

Os Peritos abarcam o estabelecimento de parcerias da equipe técnica da Vara da Infância e Juventude com os profissionais de Psicologia que exercem a função de perito do Poder Judiciário, os quais devem auxiliar a Justiça no limite de suas atribuições e "evitar qualquer tipo de interferência durante a avaliação que possa prejudicar o princípio da autonomia teórico-técnica e ético-profissional, e que possa constranger o periciando durante o atendimento" (Resolução CFP n. 008, 2010, art. $1^{\circ}$ ).

As Equipes multiprofissionais versam sobre o estabelecimento de parcerias da equipe técnica da Vara da Infância e Juventude com grupos formados por múltiplos profissionais, entre psicólogos, assistentes sociais, psiquiatras, pedagogos, advogados, com os quais o profissional de Psicologia do Judiciário poderá atuar em conjunto "desde que preserve sua especificidade e limite de intervenção, não se subordinando técnica e profissionalmente a outras áreas" (Resolução CFP n. 008, 2010, art. 5º). 
Por meio da análise dessas categorias e com o auxílio dos autores Montenegro et al. (2017) e Silva e Arpini (2013), sustenta-se a ideia de que a implementação da política de garantia do direito à convivência familiar e comunitária exige o trabalho em rede da equipe técnica da Vara da Infância e Juventude com outras equipes e profissionais capacitados (Provimento CNJ n. 36, 2014; Resolução CFP n. 008, 2010), com ampla formação teórica e prática na área dos direitos das crianças e adolescentes. No texto do ECA, encontra-se especificada a política intersetorial de atendimento às crianças e aos adolescentes, no que se refere à rede assistencial de proteção de direitos, que inclui a educação, a saúde e a assistência social, sendo efetivada por meio da colaboração dos atores da rede de atendimento e do estabelecimento de parcerias entre as equipes multidisciplinares.

\section{Acompanhamento}

A classe temática Acompanhar remete ao acompanhamento profissional de crianças e adolescentes pertencentes a famílias indígenas e dos períodos de convivência entre postulantes à adoção e crianças e adolescentes em condições de serem adotados. Sua finalidade é ouvir os gestores da política voltada para a garantia dos direitos indígenas e preparar os postulantes e as crianças e adolescentes acolhidos para o cumprimento das medidas judiciais de guarda, tutela ou adoção. Essa classe contempla as categorias Crianças e adolescentes indígenas, Contato com crianças e adolescentes em regime de acolhimento familiar ou institucional, Estágio de convivência e Colocação em família substituta.

As Crianças e adolescentes indígenas abordam o acompanhamento desse público pela equipe técnica da Vara da Infância e Juventude, a qual, como determina o inciso III, $\S 6^{\circ}$ do artigo 28 do ECA (Lei n. 8.069, 1990), acompanhará o caso com “a oitiva de representantes do órgão federal responsável pela política indigenista, no caso de crianças e adolescentes indígenas, e de antropólogos".

O Contato com crianças e adolescentes em regime de acolhimento familiar ou institucional abrange o acompanhamento do contato dos postulantes à adoção com esse público pela equipe técnica da Vara da Infância e Juventude, de acordo com o artigo $2^{\circ}$ da Lei Nacional da Adoção (Lei n. 12.010, 2009), a fim de preparar os pretendentes à adoção e as crianças e adolescentes em regime de acolhimento familiar ou institucional para a medida de colocação em família substituta.

O Estágio de convivência versa sobre o acompanhamento dessa etapa do processo de adoção pela equipe técnica da Vara da Infância e Juventude, a qual, segundo o $§ 4^{\circ}$ do artigo 
46 do ECA (Lei n. 8.069, 1990), deverá apresentar relatório detalhado sobre o deferimento da medida de colocação de crianças e adolescentes em condições de serem adotados em família substituta.

A Colocação em família substituta compreende o acompanhamento dessa medida pela equipe técnica da Vara da Infância e Juventude, a quem compete preparar, de forma gradativa, as crianças e adolescentes em condições de serem adotados para a medida de colocação em família substituta, tal como determina o artigo $2^{\circ}$ da Lei Nacional da Adoção (Lei n. 12.010, 2009).

Morelli et al. (2015) e Silva e Arpini (2013) oferecem subsídios para compreender essas categorias, ao argumentarem que o acompanhamento do processo de reintegração familiar pela equipe técnica (Lei n. 8.069, 1990; Lei n. 12.010, 2009) é antecedido pela avaliação psicossocial das condições materiais e subjetivas das famílias de origem para manter as crianças e adolescentes em seu meio. Como explicam esses autores, quando uma criança ou adolescente é encaminhado para uma instituição de acolhimento, sua família de origem precisa ser auxiliada em suas necessidades imediatas por profissionais capacitados de modo que a convivência familiar e comunitária seja restabelecida com a maior brevidade possível, a fim de garantir a preservação dos laços sociais e afetivos.

\section{Orientação}

A classe temática Orientar refere-se à orientação da inscrição de postulantes à adoção, do contato com crianças e adolescentes em condições de serem adotados, do consentimento dos titulares do poder familiar e da família substituta pela equipe técnica da Vara da Infância e Juventude a fim de esclarecer os titulares do poder familiar sobre o processo de consentimento para adoção e preparar os pretendentes à adoção para a medida de colocação de crianças e adolescentes em família substituta. Nessa classe, foram identificadas as categorias Inscrição de postulantes à adoção, Contato com crianças e adolescentes em condições de serem adotados, Consentimento dos titulares do poder familiar e Família substituta.

A Inscrição de postulantes à adoção versa sobre a orientação dos pretendentes a respeito dessa etapa do processo de adoção, que deve ser precedida pela preparação psicossocial e jurídica oferecida pela equipe técnica da Vara da Infância e Juventude. Em seu art. 50, § $3^{\circ}$, o ECA (Lei n. 8.069, 1990) determina que a orientação dos pretendentes à 
adoção ocorra "preferencialmente com apoio dos técnicos responsáveis pela execução da política municipal de garantia do direito à convivência familiar".

O Contato com crianças e adolescentes em condições de serem adotados abrange a orientação do contato dos postulantes à adoção com esse grupo, o qual deverá ser supervisionado pela equipe técnica da Vara da Infância e Juventude, de modo a prepará-los para a medida de colocação de crianças e adolescentes em condições de serem adotados em família substituta. Conforme o art. $2^{\circ}$ da Lei Nacional da Adoção (Lei n. 12.010, 2009), a preparação referida "incluirá o contato com crianças e adolescentes em condições de serem adotados [...] com apoio dos técnicos responsáveis pelo programa de acolhimento e pela execução da política municipal de garantia do direito à convivência familiar”.

O Consentimento dos titulares do poder familiar aborda a orientação dos titulares do poder familiar sobre essa etapa do processo de adoção, que será precedida por “orientações e esclarecimentos prestados pela equipe técnica da Justiça da Infância e da Juventude, em especial, no caso de adoção, sobre a irrevogabilidade da medida" (Lei n. 12.010, 2009, art. $\left.2^{\circ}\right)$.

A Família substituta compreende a orientação desse público "por intermédio de equipe técnica interprofissional a serviço do Poder Judiciário, preferencialmente com apoio dos técnicos responsáveis pela execução da política municipal de garantia do direito à convivência familiar" (Lei n. 12.010, 2009, art. 2º ). Conforme determina o Conselho Federal de Psicologia (1992), a atuação do profissional de Psicologia no Sistema de Justiça é centrada na orientação do dado psicológico, resultante de avaliação, repassado não só para a autoridade judiciária como também aos sujeitos, crianças e adolescentes e suas famílias que carecem de tal intervenção.

Com base na análise dessas categorias e nas considerações de Otuka, ScorsoliniComin e Santos (2013) e Valério e Lyra (2014), questiona-se até que ponto a procura dos postulantes pelo caminho da adoção é influenciada por concepções de adoção e família que valorizam os laços consanguíneos em detrimento dos vínculos afetivos e como isso pode dificultar a colocação de crianças e adolescentes em famílias substitutas. Para esses autores, a orientação psicossocial e jurídica dos pretendentes (Lei n. 8.069, 1990; Lei n. 12.010, 2009) precisa ser um espaço permanente de reflexão a respeito de seus temores e fantasias, e não apenas uma etapa no processo de habilitação, assim como acolher também os membros da família extensa, fornecendo suporte acerca dos aspectos psicológicos, legais e sociais que envolvem a adoção, uma vez que estão todos envolvidos na construção de significados sobre esse tema. 


\section{Preparação}

A classe temática Preparação diz respeito à preparação dos postulantes à adoção pela equipe técnica da Vara da Infância e Juventude por meio do contato com crianças e adolescentes em acolhimento familiar ou institucional em condições de serem adotados e da participação em programa oferecido pela Justiça da Infância e da Juventude com a finalidade de preparar as pessoas e casais inscritos para a medida de colocação em família substituta. Essa classe contém as categorias Contato com crianças e adolescentes em acolhimento familiar ou institucional, Programa oferecido pela Justiça da Infância e da Juventude e Pessoas e casais inscritos nos cadastros de adoção.

O Contato com crianças e adolescentes em acolhimento familiar ou institucional aborda a preparação dos postulantes para a colocação em família substituta por meio do contato com esse grupo, o qual será supervisionado pela equipe da Vara da Infância e Juventude, "com apoio dos técnicos do programa de acolhimento e da política municipal de convivência familiar", como determina o $\S 4^{\circ}$ do art. 50 do ECA (Lei n. 8.069, 1990). De acordo com o Conselho Federal de Psicologia (1992), a atribuição do profissional de Psicologia de preparação psicológica compreende o atendimento individual e em grupo dos sujeitos com vistas a facilitar o desenvolvimento de determinadas atividades, como o estabelecimento de contato com crianças e adolescentes em condições de serem adotados.

O Programa oferecido pela Justiça da Infância e da Juventude abarca a preparação dos pretendentes à adoção para a medida de colocação em família substituta pela equipe técnica da Vara da Infância e Juventude por meio desse programa, que inclui "preparação psicológica, orientação e estímulo à adoção inter-racial, de crianças maiores ou de adolescentes, com necessidades específicas de saúde ou com deficiências e de grupos de irmãos" (Lei n. 12.010, 2009, art. $2^{\circ}$ ).

As Pessoas e casais inscritos nos cadastros de adoção versam sobre a preparação psicossocial e jurídica desse público, como determina o artigo $2^{\circ}$ da Lei Nacional da Adoção (Lei n. 12.010, 2009), ofertada pela equipe técnica da Vara da Infância e Juventude, com a obrigatoriedade da participação no prazo máximo de um ano, sob pena de cassação da inscrição no cadastro de adoção.

Os desdobramentos da análise dessas categorias se alinham com as ideias defendidas por Morelli et al. (2015), para os quais, a etapa de preparação dos postulantes pela equipe técnica (Lei n. 8.069, 1990; Lei n. 12.010, 2009) não se restringe à aquisição de informações sobre a adoção, mas diz respeito à construção da parentalidade adotiva, tal como ocorre com 
os pais biológicos durante o período gestacional. De acordo com a compreensão desses autores sobre a relação adotiva entre pais e crianças ou adolescentes, o que é esperado e imaginado do filho adotivo interfere na constituição da sua subjetividade e no seu existir no mundo e no seio familiar, pois as motivações conscientes e inconscientes dos pais e a construção de espaços para diálogos são aspectos que se sobrepõem uns aos outros, o que requer o auxílio de profissionais capacitados (CFP, 1992) para ajudar a família a dar conta dessa complexidade.

\section{Considerações Finais}

O objetivo desse estudo foi analisar as ações atribuídas pelas normativas da política de adoção aos profissionais de Psicologia da Vara da Infância e Juventude. Foram submetidos à análise documental e à Análise de Conteúdo Temática o Estatuto da Criança e do Adolescente, a Lei Nacional da Adoção, o provimento do Conselho Nacional de Justiça sobre as Varas da Infância e Juventude e a resolução do Conselho Federal de Psicologia sobre a atuação do psicólogo como perito e assistente técnico no Poder Judiciário, das quais resultaram classes temáticas e categorias.

Entre as ações atribuídas pelas normativas da política de adoção aos profissionais de Psicologia da Vara da Infância e Juventude, foram identificadas a elaboração de documentos, o desenvolvimento de atividades técnicas, a prestação de assistência psicológica, a realização de oitivas, o estabelecimento de parcerias, o acompanhamento, a orientação e a preparação dos envolvidos no processo de adoção. A partir da análise dessas classes temáticas e suas respectivas categorias, pode-se perceber que essas atribuições contribuem para fundamentar as decisões judiciais, avaliar os pretendentes à adoção, auxiliá-los durante o processo, acolher e escutar suas angústias, prestar assistência qualificada e integral, oferecer suporte psicológico, legal e social e proporcionar espaços permanentes de fala, reflexão e diálogo para os envolvidos.

Chama atenção a vasta quantidade de ações atribuídas aos profissionais de Psicologia e sua natureza eminentemente técnica. Estes são responsáveis por avaliar a capacidade dos postulantes para o exercício da paternidade ou maternidade (Montenegro et al., 2017; Pereira et al., 2013; Valério e Lyra, 2014), assistir todos os envolvidos no processo de adoção (Silva \& Arpini, 2013; Valério e Lyra, 2014) e estar disponíveis para atender demandas emergentes (Otuka, Scorsolini-Comin, \& Santos, 2013; Valério \& Lyra, 2014). Este conjunto de atribuições pode gerar sobrecarga de trabalho, devido ao acúmulo de funções por esses 
profissionais, as quais exigem domínio de conhecimentos teóricos da Psicologia e de outras áreas, a fim de avaliar, acompanhar, orientar, preparar e auxiliar as partes interessadas.

Convém ressaltar também as contribuições da assistência psicológica especializada para o êxito da medida de colocação em família substituta (Morelli et al, 2015) e a importância do trabalho em rede para a garantia do direito à convivência familiar e comunitária (Montenegro et al., 2017; Morelli et al., 2015; Silva \& Arpini, 2013). Estes aspectos abrem espaço para debates sobre a formação acadêmica ofertada pelos cursos de Psicologia no Brasil, a qual continua atrelada a campos tradicionais de atuação, da clínica e das organizações, com poucos avanços em áreas emergentes, a exemplo da Psicologia jurídica.

Entre as limitações desta pesquisa, podem ser apontadas a não adoção de um aporte teórico do campo da Psicologia que auxilie na análise crítica dos resultados junto à revisão bibliográfica sobre o assunto; a impossibilidade de incluir na análise documental, em razão das proporções desse estudo, outras normativas da política de adoção que também norteiam e oferecem subsídios para a compreensão da atuação dos profissionais de Psicologia no contexto judiciário, a exemplo do Plano Nacional de Promoção, Proteção e Defesa do Direito de Crianças e Adolescentes à Convivência Familiar e Comunitária, de 2006, e da Lei n. 13.509/17; e a restrição do objeto de estudo aos profissionais de Psicologia e seu campo de atuação, não englobando outros profissionais da equipe técnica da Vara da Infância e Juventude e da rede de atendimento aos direitos das crianças e adolescentes, como assistentes sociais, pedagogos, juízes, promotores e conselheiros tutelares.

Espera-se que os achados desse estudo possam contribuir para o desenvolvimento de futuras pesquisas na área da Psicologia jurídica, por meio de diferentes aportes teóricos, técnicas e instrumentos de investigação empírica e teórica e com os demais profissionais e gestores da política de adoção e da rede de garantia do direito à convivência familiar e comunitária. Ressaltam-se os desdobramentos dessa pesquisa ao agrupar as ações atribuídas pelas normativas da política de adoção aos psicólogos, contribuindo para aprofundar o conhecimento sobre os determinantes do exercício profissional da Psicologia no campo da justiça e oferecendo subsídios para aperfeiçoar a formação acadêmica e ampliar o compromisso social dessa ciência e profissão com os direitos da infância e adolescência. 


\section{Referências}

Bardin, L. (2011). Análise de conteúdo. São Paulo, SP: Edições 70.

Brasil (1990). Lei n. 8.069, de 13 de julho de 1990. Dispõe sobre o Estatuto da Criança e do Adolescente e dá outras providências. Brasília, DF: Presidência da República. Recuperado de http://www.planalto.gov.br/ccivil_03/leis/L8069.htm

Brasil (2009). Lei n. 12.010, de 03 de agosto de 2009. Dispõe sobre adoção e dá outras providências. Brasília, DF: Presidência da República. Recuperado de http://www.planalto.gov.br/ccivil_03/_ato2007-2010/2009/lei/112010.htm

Brasil (2010). Resolução do Conselho Federal de Psicologia n. 008, de 30 de junho de 2010. Dispõe sobre a atuação do psicólogo como perito e assistente técnico no Poder Judiciário. Brasília, DF: CFP. Recuperado de http://site.cfp.org.br/wpcontent/uploads/2010/07/resolucao2010_008.pdf

Brasil (2012). Resolução do Conselho Nacional de Saúde n. 466, de 12 de dezembro de 2012. Aprova as diretrizes e normas regulamentadoras de pesquisas envolvendo seres humanos. Brasília, DF: CNS. Recuperado de http://bvsms.saude.gov.br/bvs/saudelegis/cns/2013/res0466_12_12_2012.html

Brasil (2014). Provimento do Conselho Nacional de Justiça n. 36, de 24 de abril de 2014. Dispõe sobre a estrutura e procedimentos das Varas da Infância e Juventude. Brasília, DF: CNJ. Recuperado de http://www.cnj.jus.br/images/imprensa/provimento_36.pdf

Brasil (2017). Lei n. 13.509, de 22 de novembro de 2017. Dispõe sobre adoção e dá outras providências. Brasília, DF: Presidência da República. Recuperado de http://www.planalto.gov.br/ccivil_03/_Ato2015-2018/2017/Lei/L13509.htm

Brasil (2019). Resolução do Conselho Federal de Psicologia n. 06, de 19 de março de 2019. Institui regras para a elaboração de documentos escritos produzidos pela(o) psicóloga(o) no exercício profissional. Brasília, DF: CFP. Recuperado de https://atosoficiais.com.br/lei/elaboracao-de-documentos-escritos-produzidos-pelopsicologo-decorrentes-de-avaliacao-psicologica-cfp?origin=instituicao

Conselho Federal de Psicologia. (1992). Atribuições profissionais do psicólogo no Brasil. Brasília, DF: Autor. Recuperado de http://site.cfp.org.br/leis_e_normas/atribuiesprofissionais-do-psicologo-no-brasil//

Gil, A. C. (2008). Métodos e técnicas de pesquisa social. São Paulo, SP: Atlas.

Minayo, M. C. S. (2007). O desafio do conhecimento: Pesquisa qualitativa em saúde. São Paulo, SP: Hucitec. 
Minayo, M. C. S. (Org.) (2009). Pesquisa social: Teoria, método e criatividade. Petrópolis, RJ: Vozes.

Montenegro, A. F., Rocha, L. D., \& Francileudo, F. A. (2017). Intervenção psicossocial no processo de adoção. Passagens: Revista Internacional de História Política e Cultura Jurídica, 9(1), 97-118. doi: 10.15175/1984-2503-20179106

Morelli, A. B., Scorsolini-Comin, F., \& Santeiro, T. V. (2015). O "lugar" do filho adotivo na dinâmica parental: Revisão integrativa de literatura. Psicologia Clínica, 27(1), 175194. doi: 10.1590/0103-56652015000100010

Otuka, L. K., Scorsolini-Comin, F., \& Santos, M. A. (2013). Adoção tardia por casal divorciado e com filhos biológicos. Estudos de Psicologia, 30(1) 89-99. doi: 10.1590/S0103-166X2013000100010

Pereira, C. R., Torres, A. R. R., Falcão, L., \& Pereira, A. S. (2013). O papel de representações sociais sobre a natureza da homossexualidade na oposição ao casamento civil e à adoção por família homoafetivas. Psicologia: Teoria e Pesquisa, 29(1), 79-89. doi: 10.1590/S0102-37722013000100010

Sá-Silva, J. R., Almeida, C. D., \& Guindani, J. F. (2009). Pesquisa documental: Pistas teóricas e metodológicas. Revista Brasileira de História \& Ciências Sociais, 1(1), 1-15. Recuperado de https://periodicos.furg.br/rbhcs/article/view/10351/0

Silva, M. L., \& Arpini, D. M. (2013). A Lei Nacional da Adoção: Desafios para a reinserção familiar. Psicologia em Estudo, 18(1), 125-135. doi: 10.1590/S141373722013000100013

Valério, T. A., \& Lyra, M. C. (2014). A construção cultural de significados sobre adoção: Um processo semiótico. Psicologia \& Sociedade, 26(3), 716-725. doi: 10.1590/S010271822014000300020

\section{Endereço para correspondência}

\section{Leonam Amitaf Ferreira Pinto de Albuquerque}

Universidade Federal da Paraíba

Departamento de Psicologia, Programa de Pós-Graduação em Psicologia Social

Centro de Ciências Humanas Letras e Artes, Cidade Universitária, João Pessoa - PB, Brasil. CEP 58051-900

Endereço eletrônico: leonamamitaf2@ hotmail.com

Noêmia Soares Barbosa Leal

Universidade Federal da Paraíba

Departamento de Psicologia, Programa de Pós-Graduação em Psicologia Social 
Centro de Ciências Humanas Letras e Artes, Cidade Universitária, João Pessoa - PB, Brasil. CEP 58051-900

Endereço eletrônico: noemia.barbosa@hotmail.com

\section{Maria de Fátima Pereira Alberto}

Universidade Federal da Paraíba

Departamento de Psicologia, Programa de Pós-Graduação em Psicologia Social

Centro de Ciências Humanas Letras e Artes, Cidade Universitária, João Pessoa - PB, Brasil. CEP 58051-900

Endereço eletrônico: jfalberto89@gmail.com

Recebido em: 29/10/2019

Reformulado em: 21/05/2020

Aceito em: 03/07/2020

\section{Notas}

* Doutorando e Mestre pelo Programa de Pós-Graduação em Psicologia Social da Universidade Federal da Paraíba, Membro do Núcleo de Pesquisas e Estudos sobre o Desenvolvimento da Infância e Adolescência (NUPEDIA).

** Doutoranda pelo Programa de Pós-Graduação em Psicologia Social e Mestra em Direitos Humanos, Cidadania e Políticas Públicas pela Universidade Federal da Paraíba, Membra do Núcleo de Pesquisas e Estudos sobre o Desenvolvimento da Infância e Adolescência (NUPEDIA).

*** Professora Titular do Departamento de Psicologia e do Programa de Pós-Graduação em Psicologia Social (Doutorado e Mestrado), Coordenadora do Núcleo de Pesquisas e Estudos sobre o Desenvolvimento da Infância e Adolescência (NUPEDIA), Pesquisadora 1D do CNPq.

Financiamento: Artigo elaborado a partir da Dissertação de Mestrado de Leonam Amitaf Ferreira Pinto de Albuquerque, sob a orientação da Prof. ${ }^{a}$ Dr. ${ }^{a}$ Maria de Fátima Pereira Alberto, intitulada "A atuação dos profissionais de Psicologia da Vara da Infância e Juventude na política de adoção". O presente trabalho foi realizado com apoio da Coordenação de Aperfeiçoamento de Pessoal de Nível Superior (CAPES) - Código de Financiamento 001 .

Este artigo de revista Estudos e Pesquisas em Psicologia é licenciado sob uma Licença Creative Commons Atribuição-Não Comercial 3.0 Não Adaptada. 